\title{
O MUNDO DO CORDEL A PARTIR DE UMA TIPOGRAFIA
}

\author{
MELO, Rosilene Alves de. Arcanos do verso: trajetórias da literatura de cordel. \\ Rio de Janeiro: 7Letras, 2010.
}

\section{Geraldo Magella de Menezes Neto*}

Arcanos do verso: trajetórias da literatura de cordel é fruto da dissertação de mestrado em História de Rosilene Alves de Melo pela Universidade Federal do Ceará. A autora, professora da Universidade Federal de Campina Grande, trata da trajetória da tipografia São Francisco, de propriedade de José Bernardo da Silva, na produção de folhetos de cordel entre os anos de 1939 e 1982. O estudo recebeu o prêmio "Sílvio Romero" de melhor monografia sobre cultura popular no âmbito nacional em 2003, sendo publicado pela editora 7Letras no ano de 2010.

O livro é estruturado a partir de uma interessante analogia proposta pela autora entre a trajetória da tipografia São Francisco, localizada em Juazeiro do Norte, e as cartas do tarô. Cada capítulo leva o nome de uma carta, que representa determinado momento da história da tipografia. A primeira carta, O Imperador, representa "o ímpeto inicial, a vitalidade e a força necessárias à realização de um projeto.” Remete ao percurso de José Bernardo da Silva em Juazeiro, "desde sua chegada à cidade em 1926 até o início de suas atividades como folheteiro-editor na década de trinta.” (p. 25). O segundo capítulo, A Roda da Fortuna, simboliza o sucesso, a supremacia, o triunfo, mas também a decadência, o declínio, a desagregação dos projetos. Trata do período de 1939, quando a Tipografia São Francisco é fundada, a 1956, "quando surgem os primeiros sinais da crise que afetaria a editora.” (p. 25). Já a carta da Casa da Morte "simboliza o movimento de criação versus destruição presentes

\footnotetext{
* Mestre em História Social da Amazônia pela Universidade Federal do Pará. E-mail: geraldoneto53@hotmail.com
} 
na natureza”, abordando os acontecimentos que se sucederam entre 1957 e 1982, que “resultaram no fechamento da editora e na venda de seu patrimônio.” (pp. 25-26).

Percebe-se na obra uma influência da chamada história do livro e da leitura ${ }^{1}$, notadamente expressa na afirmação de que “este estudo não está restrito apenas à hermenêutica dos textos”, mas almeja "problematizar as condições históricas de sua produção, os saberes e práticas que transitam em torno desta literatura, bem como as estratégias forjadas para a circulação desta arte entre um número cada vez maior de pessoas.” (p. 24). De fato, Rosilene Melo não se limita a analisar somente os versos dos folhetos, tão comum em pesquisas sobre a literatura de cordel. A autora leva em consideração os aspectos tipográficos dos folhetos e o processo de produção e circulação dos cordéis da tipografia São Francisco, analisando, por exemplo, as capas e quartas-capas dos folhetos da tipografia cearense. ${ }^{2}$

Além dos folhetos de cordel, Rosilene Melo utiliza como fontes jornais, documentos de cartório, almanaques e entrevistas. Dentre elas, as entrevistas ganham um maior destaque, pois revelam aos leitores os bastidores da tipografia São Francisco, o que não seria possível apenas com as fontes impressas. As entrevistas de personagens como o poeta e editor Expedito Sebastião da Silva permitem conhecer o modo como os poetas elaboram as histórias em versos e o trabalho dos tipógrafos, o processo de produção na tipografia, desde a revisão dos versos e estrofes a composição do texto nas máquinas tipográficas, até a impressão e posterior venda. Desse modo, as entrevistas são importantes no sentido de se conhecer os personagens envolvidos no processo de produção dos folhetos e entender que os impressos vão muito além da relação entre autor e leitor. ${ }^{3}$

Rosilene Melo trabalha com a ideia de que uma análise da tipografia São Francisco não é possível sem associá-la com a figura de seu proprietário, José Bernardo da Silva, que recebe uma grande atenção por parte da autora. José Bernardo chegou em Juazeiro do Norte

\footnotetext{
${ }^{1}$ André Belo afirma que mais do que apenas o livro como objeto material, "essa história compreende a comunicação e todos os processos sociais, culturais e literários que os textos afetam e envolvem.” O autor acrescenta ainda que essa área é "fortemente interdisciplinar, reunindo contribuições de várias disciplinas e de várias tradições de estudo em diferentes países.” No Brasil, de acordo com André Belo, “onde é débil a tradição bibliográfica de estudos técnicos sobre o livro antigo, os estudos que se tem desenvolvido aparecem normalmente sob a designação de 'história da leitura', não tanto como 'história do livro'.” BELO, André. História \& livro e leitura. Belo Horizonte: Autêntica, 2002, pp. 39-40.

${ }^{2}$ Roger Chartier chama a atenção para a questão da materialidade dos impressos ao afirmar que "não existe nenhum texto fora do suporte que o dá a ler, que não há compreensão de um escrito, qualquer que ele seja, que não dependa das formas através das quais ele chega ao seu leitor.” CHARTIER, Roger. A história cultural: entre práticas e representações. Rio de Janeiro: Bertrand, 1990, p. 127.

${ }^{3}$ Nessa perspectiva, Robert Darnton sugeriu um "circuito de comunicação” dos livros. Esse circuito é um modelo proposto para analisar como os livros surgem e se difundem entre a sociedade. Este pode ser descrito como um circuito de comunicação que "vai do autor ao editor (se não é o livreiro que assume esse papel), ao impressor, ao distribuidor, ao vendedor, e chega ao leitor”. DARNTON, Robert. O beijo de Lamourette: mídia, cultura e revolução. São Paulo: Cia. das Letras, 1990, p. 112.
} 
no ano de 1926, inicialmente vendendo nas ruas da cidade remédios caseiros, raízes e miçangas. Aos poucos, introduziu os folhetos, que se tornou um dos produtos com o qual obtinha mais lucros. O contato direto com os leitores-ouvintes permitiu a José Bernardo da Silva tornar-se um profundo conhecedor do gosto e das expectativas do público, ao observar os títulos que tinham maior saída. Essa experiência se revelou mais tarde como fundamental para o sucesso que a sua editora veio alcançar. (p. 56). A autora aponta que a escolha da poesia em verso como atividade comercial se justificava, "em primeiro lugar, pelo lucro obtido com a venda dos livros”, já que a venda dos folhetos era um meio de sobrevivência possível para aqueles que buscavam fugir da miséria. (p. 57).

Rosilene Melo investiga o contexto que levou a tipografia São Francisco a se tornar a mais importante editora de folhetos no Brasil a partir dos anos 1950, bem como a cidade de Juazeiro como a mais nova referência da literatura de cordel no país na época. A autora relaciona a ascensão da tipografia com a conjuntura econômica nacional favorável, com a relativa estabilidade monetária e o aumento do poder aquisitivo dos agricultores, principais compradores de folhetos. A autora acrescenta também que José Bernardo se beneficiou da crise das editoras concorrentes, como das editoras de Francisco das Chagas Batista, João Martins de Athayde, Francisco Rodrigues Lopes e Olegário Pereira Neto. (p. 78).

A aquisição das obras de propriedade de João Martins de Athayde em 1949 por José Bernardo contribuiu para o sucesso da tipografia cearense, já que o editor passou a ter os direitos autorais dos folhetos de Leandro Gomes de Barros, principal poeta de cordel e que tinha a preferência dos leitores, tendo assim garantida a "saída" de grande quantidade de folhetos. Somam-se a isso as estratégias utilizadas por José Bernardo para diminuir os custos de produção e acelerar a distribuição de folhetos, tais como: o uso da xilogravura nas capas do cordel, pois utilizava uma matéria-prima fartamente disponível na zona rural, a madeira, e poderia ser produzida em pouquíssimo tempo por artesãos contratados (p. 110); a exploração nas relações de trabalho, já que por volta de 1948 José Bernardo tinha cerca de 12 pessoas trabalhando dia e noite na confecção dos impressos, e nenhum dos trabalhadores estava em situação regular (p. 86), além do emprego da mão de obra de mulheres e de crianças, cuja remuneração é historicamente mais baixa. (p. 98); e a aquisição de novos equipamentos, com os quais era possível imprimir diariamente até 10.000 romances de 32 páginas. (p. 97).

Utilizando uma vasta documentação, Rosilene Melo também aponta as condições que levaram à crise da tipografia São Francisco, tais como: a concorrência com novas tipografias a partir dos anos 1960, o aumento nos custos de produção dos folhetos, inflação, modernização do setor gráfico e problemas administrativos entre os herdeiros da empresa. (p. 131). Tais 
fatores levantados por Rosilene Melo são importantes no sentido de revisar teses bastante disseminadas ainda hoje, que atribuem ao rádio e a televisão o motivo da crise da literatura de folhetos a partir da década de 1960. Segundo a autora, “foi mais fácil encontrar um álibi, um algoz, para responsabilizar pela crise da produção de folhetos” do que "analisar como condições históricas singulares possibilitaram a queda das vendas e a falência das principais tipografias brasileiras.” (p. 130).

Pode-se acusar a autora de por vezes adotar um tom panfletário na obra, notadamente quando ela trata do estado atual da tipografia, hoje com a denominação de Lira Nordestina, e sob a responsabilidade da Universidade Regional do Cariri (URCA). A autora critica, por exemplo, a "segregação" entre as instituições oficiais que se propõem a "proteger” a literatura de folhetos dos sujeitos que enfrentam, no cotidiano, a árdua tarefa de espalhar essas folhas volantes. Tal "segregação” foi observada pela autora na inauguração das novas instalações da Lira Nordestina em 1988, na qual aparecem nas fontes jornalistas, intelectuais, pró-reitores e representantes da Igreja Católica. Entretanto em nenhum dos registros fotográficos aparecem os trabalhadores da Lira Nordestina, sendo o mais ilustre ausente o poeta Expedito Sebastião da Silva. (p. 170).

Além disso, Rosilene Melo aponta que a "estatização” da tipografia tem se mostrado desastrosa, já que sucessivos problemas de administração, falta de projeto editorial, falta de uma política para a editora pela instituição dirigente, a Universidade Regional do Cariri são alguns dos problemas que impediram o bom funcionamento da editora desde a estatização (p. 175). Tal discurso panfletário expresso no final da obra não deixa de expressar o envolvimento da autora com o seu objeto de pesquisa, envolvimento este que se mostra positivo, já que demonstra uma preocupação com o futuro da editora e ressalta a sua importância histórica e cultural para a cidade de Juazeiro do Norte.

Desse modo, Arcanos do verso é uma excelente contribuição para os estudos dos livros e da literatura de cordel. Rosilene Melo demonstra estar bastante sintonizada com os debates historiográficos sobre o cordel e traz importantes perspectivas para esse campo de estudos. Ao mesmo tempo em que o caso da tipografia São Francisco é singular, a partir dela podemos estabelecer novas abordagens da produção e circulação dos folhetos de cordel no Brasil. Além disso, evidencia a possibilidade de múltiplas pesquisas sobre Juazeiro do Norte, cidade muitas vezes reduzida à figura do Padre Cícero, personagem tradicionalmente associado a essa localidade. 